Article

\title{
Significant Factors Influencing Rural Residents' Well-Being with Regard to Electricity Consumption: An Empirical Analysis in China
}

\author{
Sen Guo *, Huiru Zhao, Chunjie Li, Haoran Zhao and Bingkang Li \\ School of Economics and Management, North China Electric Power University, Beijing 102206, China; \\ zhaohuiru@ncepu.edu.cn (H.Z.); lichunjie@ncepu.edu.cn (C.L.); haoranzhao0118@163.com (H.Z.); \\ libingkang@163.com (B.L.) \\ * Correspondence: guosen@ncepu.edu.cn; Tel.: +86-10-6177-3084 \\ Academic Editor: Marc A. Rosen \\ Received: 21 September 2016; Accepted: 1 November 2016; Published: 3 November 2016
}

\begin{abstract}
The electric universal service policy, which has been implemented for many years in China, aims to meet the basic electricity demands of rural residents. Electricity consumption can facilitate the daily life of rural residents, such as lighting and cooking, which are necessary to their well-being. In practice, the well-being of rural residents due to electricity consumption is influenced by many factors. Therefore, to improve the well-being of rural residents, it is quite necessary to identify and optimize the significant factors that make the electric universal service policy play its prescribed role as well as possible. In this paper, the significant factors influencing rural residents' well-being obtained from electricity consumption were identified and discussed by employing the Ordered Probit model. The results indicate that: (1) there are six significant factors, of which 'educational level', 'health condition', 'each person income of a family per month', and 'service time of household appliances' play positive roles in rural residents' well-being, while 'average power interruption times' and 'monthly electric charges' have negative impacts; (2) for significant factors with positive roles, 'educational level' and 'health condition' show larger marginal effects on rural residents' well-being; and (3) for significant factors with negative impacts, 'average power interruption times' has the greatest marginal effect. Finally, policy implications are proposed for improving rural residents' well-being, which can also contribute to the effective implementation of the electric universal service policy in China.
\end{abstract}

Keywords: well-being; electricity consumption; rural residents; significant factors; Ordered Probit model; China

\section{Introduction}

Electric energy plays an important role in contemporary economic, social and human development [1,2]. As a basic energy industry of the national economy, the electric power industry can provide an important material basis for people's lives and socio-economic development. Electric universal service (EUS), as a kind of social responsibility taken by state-owned power grid enterprises, is meant to meet the basic electricity demand for backward and vulnerable groups, and holds the characteristic of commonweal [3,4]. Therefore, it is more important than other commonweal services provided by utility companies. As an important public function of government, EUS aims to enable all citizens to receive basic electric service with a reasonable and acceptable price and without consideration of regional restriction. The implementation of EUS is an important way for Chinese government to undertake the public service function and fulfill social responsibility [5]. In recent years, the Chinese government has promulgated several policies and implemented strategic measures related 
to EUS, such as 'China's Energy Policy (2012)' promulgated by the State Council of China, the 'Twelfth Five-Year Plan of Energy Development' made by the State Council of China, and the 'Three-year action plan for comprehensively solving electric usage problems for rural residents (2013-2015)' issued by the National Energy Administration. Owing to those related policies and measures, those living in the remote and backward regions, especially rural residents, can access electric energy. Nowadays, most rural residents use electric energy in daily life, such as lighting, cooking, and watching TV, which brings convenience to rural residents' lives and improves their living quality.

Well-being, as a kind of subjective spiritual feeling, represents a kind of satisfactory state of a person regarding his/her life [6]. In philosophy, well-being refers to how well a person's life goes for the person who lives it. In economics, well-being is used for one or more quantitative measures intended to access the life quality of a person or a group [7]. Well-being is an individual sensuous response to current living conditions or economic and social activities, which is an important means to measure the individual's happiness level [8,9]. Individual well-being is a complex conceptual system related to many disciplines such as philosophy, psychology, sociology, and economics. Well-being usually reflects individual cognitive thinking and psychological sentiments and is influenced by many factors, such as individual characteristic, economic condition and social status [10]. Studies on individual well-being are a current area of research emphasis and difficulty in the field of welfare economics $[11,12]$. As a government-oriented public service, the EUS is provided by electric power enterprises in China, which can give rural residents living in remote or backward areas access to electric energy [3]. The electricity consumption (such as lighting, cooking and watching TV) of rural residents owing to EUS implementation will facilitate their daily life, which can improve their well-being and promote their sustainable development. The well-being of rural residents due to electricity consumption is influenced by many factors, such as educational background, health condition and individual income. However, different factors may have different impacts on individual well-being. Therefore, it is quite important to identify the key and significant factors, and then the well-being of rural residents can be improved by perfecting those significant factors, which can have targeted policy implications for relevant policy makers and make the EUS policy play its prescribed role as well as possible, which can promote sustainable implementation of related EUS policy.

The well-being of rural residents due to electricity consumption is the subjective feelings and psychological evaluation of rural residents on electric usage, which can be measured via a plurality of ordered ratings, such as 'Very satisfied', 'Generally satisfied', and 'Dissatisfied'. Therefore, the well-being evaluation of rural residents is discrete, ordered and multivariable. The Ordered Probit model is an econometric method suitable for the discrete, ordered and multi-grade issues [13]. In statistics, Ordered Probit is a generalization of popular Probit analysis to the case of more than two outcomes of an ordinal dependent variable, which has been widely applied in many fields, such as internationalization choices [14], the monetary policy stance measure of the People's bank of China [15], determinants of life satisfaction in Albania [16], US bond default forecasting [17], the factors affecting credit rating [18], and so on. However, the Ordered Probit model has unfortunately rarely been employed in the field of electric power, and this method may be quite suitable for some electricity-related issues, such as the well-being of individuals due to electricity consumption. In this paper, the well-being of rural residents due to electricity consumption is studied by attempting to employ the Ordered Probit model. Considering the population's sociological factors, economic factors and electricity consumption behavioral factors, the significant factors influencing the well-being of rural residents due to electricity consumption are identified by employing the Ordered Probit technique with practical data obtained from on-the-spot visits and questionnaire surveys. Finally, several policy recommendations are proposed for further improving the well-being of rural residents, which can also contribute to the effective and sustainable implementation of EUS policy in China.

Section 2 reviews the existing research related to the electricity consumption of rural residents; the Ordered Probit model, variable (factor) selection, and data sources are described in Section 3; 
the empirical analysis is performed in Section 4; and Section 5 lists the main findings and policy implications.

\section{Literature Review}

Considering the economic efficiency and regional discrepancy, rural electrification mainly depends on the EUS policy implemented by the Chinese government. Currently, the domestic research and foreign research on rural electrification are quite different. For domestic research, because the EUS policy is very important for rural residents who live in remote and backward regions accessing electric energy, current studies mainly focus on how to effectively formulate and implement EUS policy.

Universal service, first proposed in the field of industry, is mainly to solve the contradiction between the social service function and profit target of the network industry. In 2002, the concept of 'universal service' was proposed in the files related to electric power system reform promulgated by the China State Council, which marked that the electric universal service had been officially proposed in China [19]. In China, related studies focus on the connotation, social welfare measurement and implementation mechanism of EUS. Wang J. and Gao W. examined the electricity demand of rural residents, accessing approach and relative regulatory policies in the background of electric power system reform [20]. Liao J. and $\mathrm{Wu} \mathrm{C}$. analyzed the electricity supply subjects for rural residents living in remote and backward regions under the modes of vertical integration and transmission-distribution-sale integration, and corresponding subsidy mechanisms were designed [21]. Cai J. reviewed the EUS and electricity supply for rural residents in China, and explored several key issues including government duty and legislation, policy classification and standards as well as the quality and price of EUS [22]. In terms of social welfare measurement, Li C. et al. evaluated the comprehensive effectiveness of power supply in rural areas including the three subjects of society, enterprise and residents by applying an eigenvalue method and coordination degree hybrid model [23]. Zhao $\mathrm{H}$. et al. quantitatively examined the efficiency of power supply in rural areas and the coordination between power supply and regional economic development by using DEA and coordinated development theory, and then comprehensively measured the social value of EUS [24]. From the perspective of sustainability, Zhao $\mathrm{H}$. et al. constructed the social welfare measure function for electricity consumption of rural residents by employing expected utility theory and prospect theory, and performed the empirical analysis by taking Yunnan province as example [3]. In terms of implementation mechanism of EUS, Zhao H. et al. firstly analyzed the factors affecting electricity demand of rural residents, and then built an income compensation model for EUS based on a Keynesian consumption function [25]. Chi N. et al. analyzed the funding mechanism of EUS, examined the cost of switching from the original cross-subsidy mechanism to a funding mechanism, and constructed a decision model for the best time to switch [26].

For foreign research, the recent researchers mainly focus on how to effectively provide electric energy for rural residents, such as using a distributed power supply and micro-grid. Hoque N. and Kumar S. analyzed the composition, layout and effectiveness of home solar systems for proving electric energy for residents living in remote areas in Bangladesh [27]. Williams A. and Simpson R. explored the technical requirements, successful experiences and influencing factors of electricity provision for British residents in remote areas using small hydropower [28]. Saheb-Koussa D. et al. investigated the technological economy of a wind-photovoltaic-diesel hybrid power system by which the rural residents can access electricity in Algeria, and the optimal composition of a wind-solar-oil hybrid power system was also studied [29]. Lay J. et al. studied the feasibility of distributed solar home systems and conventional lighting fuel power generation system for providing electricity to rural residents in Kenya [30]. Gómez M.F. et al. analyzed the important challenges faced by rural electrification initiative Luz Para Todos-LPT (Light for All) in the Brazilian Amazon, and proposed several measurements to promote the LPT, such as developing distributed power generation techniques and optimizing subsidies [31]. Shaahid S.M. and El-Amin I. assessed the techno-economic feasibility of hybrid PV-diesel-battery power systems for rural electrification in Saudi Arabia using NREL's HOMER 
software [32]. Bhattacharyya S.C. comprehensively reviewed the energy access situation of rural areas in India and analyzed the main problems, and finally discussed whether the rural electrification can resolve the energy access issue in India [33]. Urmee T. et al. performed a literature review on renewable-based rural electrification to analyze the causes of slow progress in providing electricity to rural residents in developing countries in Asia and the Pacific, and proposed suggestions for rural electrification implementation in these countries [34].

Overall, the current foreign studies mainly focus on the economic and technological feasibility of adopting distributed power generation techniques to provide electricity for rural residents, which can also be summarized as the implementation path of rural electrification. However, in China, the marketization reform of the electric power system is in progress. Power grid extension and distributed power generation are two main paths for rural electrification in China. Close attention is paid by Chinese scholars to the implementation subjects and compensation mechanisms of those two paths. It can be said that the current study remains to be enriched and improved. The existing literature studying the rural electrification in China are mainly from the angles of government (the subject of liability) and electric power enterprises (the subject of implementation). However, there is little related research from the perspective of rural residents (the recipients), not to mention the well-being of rural residents due to electricity consumption. Therefore, the significant factors influencing the well-being of rural residents due to electricity consumption are studied in this paper, which can fill the current research gap. The study in this paper is of great practical value and can provide references for improving the well-being of rural residents and playing the prescribed role of EUS policy as well as possible.

\section{Model, Variables and Data Source}

\subsection{Ordered Probit Model}

As a kind of multi-grade discrete choice model, the Ordered Probit model can build a relationship between a non-continuous sequenced dependent variable and explanatory variables, and has been widely used for many practical issues. Different from the Probit model, in the Ordered Probit model, the dependent variable is multi-grade, ordered and discrete, while the explanatory variables are a set of many factors influencing the dependent variables, which can be discrete or continuous. The basic principle of the Ordered Probit model is expounded as follows.

Referring to some well-being quantification-related literatures, in this paper, we suppose that the dependent variable $y$, the well-being of rural residents due to electricity consumption, can be represented by five grades, namely "very dissatisfied (VD)", "not satisfied (NS)", "generally satisfied (GS)", "relatively satisfied (RS)" and "very satisfied (VS)". The explanatory variables $x$ are composed of a set of factors influencing rural residents' well-being. When using the multi-grade discrete variable $y$ as a dependent variable to perform regression analysis with explanatory variables, there may be inconformity and heteroscedasticity. Therefore, it needs to convert discrete dependent variable $y$ to continuous dependent variable $y^{*}$. Suppose there is a continuous dependent variable $y^{*}$ that cannot be directly observed, but it can be expressed as a continuous function of explanatory variable $x$ as follows:

$$
y^{*}=\beta x+\varepsilon
$$

where $y^{*}$ is the converted dependent variable (also called as decision preference), $x=\left[x_{1}, x_{2}, \ldots, x_{\mathrm{n}}\right]$ are a set of $n$ explanatory variables, $\beta=\left[\beta_{1}, \beta_{2}, \ldots, \beta_{n}\right]$ are the parameters to be estimated in regression model which indicate the contribution degree of $n$ explanatory variables to dependent variable $y^{*}$, and $\varepsilon$ is random disturbance which represents other neglected factors that affect $y^{*}$. Meanwhile, $\varepsilon$ obeys the standard normal distribution, namely $\varepsilon \sim N(0,1)$.

Equation (1) is also called the latent regression equation of the Ordered Probit model. In practice, $y^{*}$ cannot be directly measured, and needs to be obtained by $y$ indirectly. 
Let $\alpha_{1}<\alpha_{2}<\cdots<\alpha_{j-1}$ be the unknown cutting points (also called threshold parameters). Because $y$ is represented by five grades in this paper, there are four cutting points, namely $\alpha_{1}, \alpha_{2}, \alpha_{3}$ and $\alpha_{4}$. The relationship between $y$ and $y^{*}$ is shown as below:

$$
y= \begin{cases}1, & \text { if } y^{*} \leq \alpha_{1} \\ 2, & \text { if } \alpha_{1}<y^{*} \leq \alpha_{2} \\ 3, & \text { if } \alpha_{2}<y^{*} \leq \alpha_{3} \\ 4, & \text { if } \alpha_{3}<y^{*} \leq \alpha_{4} \\ 5, & \text { if } y^{*}>\alpha_{4}\end{cases}
$$

Thus, the probability of $y$ for each grade value can be computed via Equation (3) as follows:

$$
\left\{\begin{array}{l}
P(y=1 \mid x)=P\left(y^{*} \leq \alpha_{1} \mid X\right)=P\left(\beta x+\varepsilon \leq \alpha_{1} \mid X\right)=\Phi\left(\alpha_{1}-\beta x\right) \\
P(y=2 \mid x)=P\left(\alpha_{1}<y^{*} \leq \alpha_{2} \mid X\right)=P\left(\alpha_{1}<\beta x+\varepsilon \leq \alpha_{2} \mid X\right)=\Phi\left(\alpha_{2}-\beta x\right)-\Phi\left(\alpha_{1}-\beta x\right) \\
P(y=3 \mid x)=P\left(\alpha_{2}<y^{*} \leq \alpha_{3} \mid X\right)=P\left(\alpha_{2}<\beta x+\varepsilon \leq \alpha_{3} \mid X\right)=\Phi\left(\alpha_{3}-\beta x\right)-\Phi\left(\alpha_{2}-\beta x\right) \\
P(y=4 \mid x)=P\left(\alpha_{3}<y^{*} \leq \alpha_{4} \mid X\right)=P\left(\alpha_{3}<\beta x+\varepsilon \leq \alpha_{4} \mid X\right)=\Phi\left(\alpha_{4}-\beta x\right)-\Phi\left(\alpha_{3}-\beta x\right) \\
P(y=5 \mid x)=P\left(y^{*}>\alpha_{4} \mid X\right)=P\left(\beta x+\varepsilon>\alpha_{4} \mid X\right)=1-\Phi\left(\alpha_{4}-\beta x\right)
\end{array}\right.
$$

where $\Phi(\cdot)$ represents the density function of standard normal distribution.

Although $y^{*}$ is unobservable, the range that $y^{*}$ belongs to can be determined. Therefore, we can correlate $y^{*}$ with the probability of $y^{*}$ belonging to the range according to a certain known distribution, and then the estimated value of parameter $\beta$ can be obtained using the maximum likelihood estimation method based on the sample probabilities of different ranges that $y^{*}$ belongs to.

After the latent regression equation is built, the marginal contribution of each explanatory variable can be calculated, which can explore the influence direction (positive or negative) and influence degree of each explanatory variable $x=\left[x_{1}, x_{2}, \ldots, x_{n}\right]$ on dependent variable $y$. The marginal contribution of an explanatory variable refers to the fact that under the condition of other explanatory variables taking average values, the change in the probability of the dependent variable takes certain value that arises when the explanatory variable value changes by one unit, which can be measured by

$$
\left\{\begin{array}{l}
\partial p_{1}(x) / \partial x_{k}=\beta_{k} \Phi\left(\alpha_{1}-\beta x\right) \\
\partial p_{j}(x) / \partial x_{k}=\beta_{k}\left[\Phi\left(\alpha_{1}-\beta x\right)-\Phi\left(\alpha_{j}-\beta x\right)\right] \\
\partial p_{5}(x) / \partial x_{k}=\beta_{k} \Phi\left(\alpha_{5}-\beta x\right) \\
2<j<4
\end{array}\right.
$$

\subsection{Variables Selection}

The selection of explanatory variables, namely the factors possibly influencing the well-being of rural residents due to electricity consumption, is very important. In this paper, the initial possible influencing factors were selected based on consulting a large number of literatures. Then, those selected factors were further screened by way of on-the-spot visits and expert consultation. Finally, the final influencing factors were determined, which include demographical and sociological factors, economic factors and electric usage behavior factors.

(1) Demographical and sociological factors: These factors aim to reflect the personal features and heterogeneous characteristics of rural residents, which include age, gender, educational level, household population, and health condition.

(2) Economic factors: This kind of factors mainly characterize the economic conditions and situations of rural residents, which include each person income of a family per month, income satisfaction, and income source.

(3) Electric usage behavior factors: This kind of factors represent the electric consumption features and patterns of rural residents in a certain economic and social environment, which 
include average power interruption times, monthly electric charge, and service time of household appliances.

The detailed connotations and valuing characteristics of factors are listed in Table 1.

The well-being of rural residents due to electricity consumption is the dependent variable in this paper. According to the design principle of Likert's 5-level scale, the well-being of rural resident is divided into five grades, namely "very dissatisfied (VD)", "not satisfied (NS)", "generally satisfied (GS)", "relatively satisfied (RS)" and "very satisfied (VS)". The connotations and value characteristics of this dependent variable are also listed in Table 1.

Table 1. The connotations and value characteristics of variables.

\begin{tabular}{|c|c|c|c|c|c|}
\hline Classification & Variables & Variable Name & Variable Connotation & $\begin{array}{l}\text { Variable } \\
\text { Value }\end{array}$ & Explanation of Variable Value \\
\hline $\begin{array}{l}\text { Dependent } \\
\text { variable }\end{array}$ & $\mathrm{Y}$ & $\begin{array}{l}\text { Well-being of } \\
\text { rural residents }\end{array}$ & $\begin{array}{l}\text { Subjective feeling and } \\
\text { evaluation of rural } \\
\text { residents on electricity } \\
\text { consumption }\end{array}$ & $1-5$ & $\mathrm{VD}=1, \mathrm{NS}=2, \mathrm{GS}=3, \mathrm{RS}=4, \mathrm{VS}=5$ \\
\hline \multirow{3}{*}{$\begin{array}{l}\text { Demographical } \\
\text { and } \\
\text { sociological } \\
\text { factors }\end{array}$} & $\mathrm{X} 1$ & Age & Individual living time & $1-8$ & $\begin{array}{c}0-12 \text { years old }=1,12-18 \text { years old }=2, \\
18-30 \text { years old }=3,30-40 \text { years old }=4, \\
40-50 \text { years old }=5,50-60 \text { years old }=6, \\
60-70 \text { years old }=7, \text { over } 70 \text { years old }=8\end{array}$ \\
\hline & $\mathrm{X} 2$ & Gender & $\begin{array}{l}\text { The difference between } \\
\text { male and female }\end{array}$ & $0-1$ & male $=0$, female $=1$ \\
\hline & $\mathrm{X} 3$ & $\begin{array}{c}\text { Educational } \\
\text { level }\end{array}$ & $\begin{array}{l}\text { The degree of education } \\
\text { received by rural } \\
\text { residents }\end{array}$ & $1-5$ & $\begin{array}{c}\text { primary and under }=1, \text { junior high school }=2, \\
\text { senior high school }=3, \text { college }=4, \\
\text { undergraduate and above }=5\end{array}$ \\
\hline \multirow{3}{*}{$\begin{array}{l}\text { Economic } \\
\text { factors }\end{array}$} & $\mathrm{X} 6$ & $\begin{array}{l}\text { Each person } \\
\text { income of a } \\
\text { family per } \\
\text { month }\end{array}$ & $\begin{array}{l}\text { Economic gain of a } \\
\text { family divided by } \\
\text { population number } \\
\text { per month }\end{array}$ & $1-10$ & $\begin{array}{c}500 \text { yuan and below }=1,500-800 \text { yuan }=2, \\
800-1100 \text { yuan }=3,1100-1500 \text { yuan }=4, \\
1500-2000 \text { yuan }=5,2000-2500 \text { yuan }=6, \\
2500-3000 \text { yuan }=7,3000-4000 \text { yuan }=8, \\
4000-5000 \text { yuan }=9,5000 \text { yuan and more }=10\end{array}$ \\
\hline & $\mathrm{X} 7$ & $\begin{array}{l}\text { Income } \\
\text { satisfaction }\end{array}$ & $\begin{array}{l}\text { Subjective feeling and } \\
\text { evaluation on income } \\
\text { of individual }\end{array}$ & $1-5$ & $\mathrm{VS}=1, \mathrm{NS}=2, \mathrm{GS}=3, \mathrm{RS}=4, \mathrm{VS}=5$ \\
\hline & $\mathrm{X} 8$ & Income sources & $\begin{array}{l}\text { Approach of individual } \\
\text { revenues acquired }\end{array}$ & $1-5$ & $\begin{array}{c}\text { None }=1, \text { farming }=2, \text { workshops }=3, \\
\text { work at factory }=4, \text { other }=5\end{array}$ \\
\hline $\begin{array}{l}\text { Electric usage } \\
\text { behavior } \\
\text { factors }\end{array}$ & $\mathrm{X} 11$ & $\begin{array}{l}\text { Service time of } \\
\text { household } \\
\text { appliances }\end{array}$ & $\begin{array}{l}\text { Total usage time of } \\
\text { household appliances of } \\
\text { a family every day }\end{array}$ & $n$ & Numerical variable \\
\hline
\end{tabular}

\subsection{Data Source}

The data used in this paper were obtained through on-the-spot visits and questionnaire surveys at Yunnan province in China. As one of the key provinces where the EUS is implemented, Yunnan province is located on the southwest border of China, and is a mountainous frontier region with a minority population and significant poverty. In 2005, the project 'Providing electric energy for rural residents living in remote and backward regions' was launched. In the past ten years, popularizing power-supply projects with a total investment of 3.458 billion RMB yuan have been built, which give nearly 0.32 million of rural residents access to electric energy and increase the electrified rate to more than $99.2 \%$. 
Face-to-face interview and questionnaire distribution are two main ways to obtain the data on related factors (variables) used in this paper. For face-to-face interviews, we communicated with rural residents through the asking and answering method, which can make rural residents conscientiously express their thoughts. Finally, 702 valid questionnaires were obtained. For questionnaire surveys, 1020 questionnaires were distributed, and the survey location was the power supply station in the township. When the rural residents paid the electricity bills at the power supply station, they will be asked to fill out questionnaires. Finally, 845 valid questionnaires were obtained by this way, and the valid return rate is $82.84 \%$. Finally, a total of 1547 valid questionnaires were obtained which are used in this paper, and the valid return rate is $89.84 \%$.

\section{Empirical Analysis}

\subsection{Questionnaire Reliability Analysis}

Before using the results of questionnaire survey to identify significant factors influencing the well-being of rural residents due to electricity consumption, a reliability analysis on questionnaires needs to be conducted. Cronbach's Alpha $(\alpha)$ is commonly used as an indicator to analyze the reliability of questionnaires with multiple Likert questions [35]. When the value of Cronbach's $\alpha$ is greater than 0.7, the questionnaire results show high reliability; when the value of Cronbach's $\alpha$ is less than 0.35, the questionnaire results show low reliability; and when Cronbach's $\alpha$ value is between 0.35 and 0.7, the questionnaire results can be considered as reliable [36].

By using the 'Reliability Analysis' command in SPSS Statistics, the reliability test result of the 1547 questionnaires used in this paper can be obtained, as listed in Table 2. From Table 2, it can be seen that the Cronbach's $\alpha$ of demographical and sociological factors is 0.602 , which indicates it is reliable. Cronbach's $\alpha$ of economic factors, electric usage behavior factors, and the whole questionnaires are all larger than 0.7 , which show high reliabilities.

Reliability tests were also conducted for the case that deletes a certain question (namely any one of 12 variables) from the questionnaire, and the results are shown in Table 3 . It can be seen that the reliability after deleting any one question of the original questionnaire will decrease, becoming less than the reliability of 0.748 for the original questionnaire. This reliability analysis result also demonstrates the design of the original questionnaire is reasonable, and the survey results obtained from questionnaires are effective and reliable, which can be used for identifying significant factors influencing the well-being of rural residents due to electricity consumption.

Table 2. Reliability test result.

\begin{tabular}{ccc}
\hline Item & Cronbach's $\alpha$ & Numbers of Variables \\
\hline Overall & 0.748 & 12 \\
Demographical and sociological factors & 0.602 & 5 \\
Economic factors & 0.717 & 3 \\
Electric usage behavior factors & 0.823 & 3 \\
\hline
\end{tabular}

Table 3. Reliability test results after deleting any one variable.

\begin{tabular}{ccccc}
\hline Variable & Age & Gender & Educational Level & Household Population \\
\hline $\begin{array}{c}\text { Cronbach's } \alpha \text { after } \\
\text { deleting this variable }\end{array}$ & 0.731 & 0.702 & 0.682 & 0.613 \\
\hline Variable & Health condition & $\begin{array}{c}\text { Each person income of a } \\
\text { family per month }\end{array}$ & Income satisfaction & Income sources \\
\hline $\begin{array}{c}\text { Cronbach's } \alpha \text { after } \\
\text { deleting this variable }\end{array}$ & 0.608 & 0.681 & 0.654 & 0.716 \\
\hline Variable & $\begin{array}{c}\text { Average power } \\
\text { interruption times }\end{array}$ & Monthly electric charge & $\begin{array}{c}\text { Service time of } \\
\text { household appliances }\end{array}$ & $\begin{array}{c}\text { Well-being of rural } \\
\text { residents }\end{array}$ \\
\hline $\begin{array}{c}\text { Cronbach's } \alpha \text { after } \\
\text { deleting this variable }\end{array}$ & 0.721 & 0.702 & 0.689 & 0.658 \\
\hline
\end{tabular}




\subsection{Descriptive Statistics of Survey Results}

Of the 1547 returned questionnaires, 473 rural residents (accounting for 30.58\%) are very satisfied with their electricity consumption, 776 rural residents (50.16\%) are relatively satisfied and 246 rural residents $(15.9 \%)$ are generally satisfied. However, there are still 30 rural residents (accounting for $1.94 \%)$ who are not satisfied with their electricity consumption and 22 rural residents who $(1.42 \%)$ are very dissatisfied with their electricity consumption.

The specific descriptive statistical results of 12 variables are listed in Table 4 . It can be seen that the average well-being grade value of rural residents is 4.06 , which indicates that the respondents have a higher degree of satisfaction with electricity consumption. The average grade value of variable 'age' is 4.87 , indicating that majority of respondents are $40-50$ years old. The average grade value of variable 'gender' is 0.44 , showing that there are slightly more male respondents than female ones. The average grade value of variable 'educational level' is 2.83 , revealing that majority of respondents are junior and senior high school graduates. From the view of overall average, some respondents are satisfied with current electricity consumption, and they generally have good health. Meanwhile, a family has four persons on average, 60-70 yuan of electricity charges per month, and $3.24 \mathrm{~h}$ of service time for household appliances.

Table 4. Descriptive statistical results of all variables.

\begin{tabular}{|c|c|c|c|}
\hline & Variables & Mean & Standard Deviation \\
\hline Dependent variable & Well-being of rural residents $(\mathrm{Y})$ & 4.06 & 0.07 \\
\hline \multirow{5}{*}{$\begin{array}{l}\text { Demographical and } \\
\text { sociological factors }\end{array}$} & Age $(X 1)$ & 4.87 & 0.09 \\
\hline & Gender (X2) & 0.44 & 0.04 \\
\hline & Educational level (X3) & 2.83 & 0.11 \\
\hline & Household population (X4) & 4.17 & 0.12 \\
\hline & Health condition (X5) & 3.52 & 0.08 \\
\hline \multirow{3}{*}{ Economic factors } & Each person income of a family per month (X6) & 6.03 & 0.21 \\
\hline & Income satisfaction (X7) & 2.80 & 0.07 \\
\hline & Income sources (X8) & 3.92 & 0.10 \\
\hline \multirow{3}{*}{$\begin{array}{l}\text { Electricity consumption } \\
\text { behavior factors }\end{array}$} & Average power interruption times (X9) & 1.65 & 0.04 \\
\hline & Monthly electric charge (X10) & 7.19 & 0.23 \\
\hline & Service time of household appliances (X11) & 3.24 & 0.15 \\
\hline
\end{tabular}

\subsection{Result Analysis}

The significant factors influencing the well-being of rural residents due to electricity consumption and the corresponding influence degree can be obtained by employing the Ordered Probit model, and the results are listed in Table 5. It should be noted that the estimated coefficients obtained from the Ordered Probit model cannot measure the marginal effect of explanatory variables. Therefore, the marginal effects of explanatory variables on the well-being of rural residents were also evaluated after constructing the Ordered Probit regression equation, and the results are listed in Table 6.

Table 5. Estimation results of the Ordered Probit model.

\begin{tabular}{cccc}
\hline Explanatory Variables & Coefficient & Z-Statistic & $p>|z|$ \\
\hline Age & 0.0737 & 0.7432 & 0.4592 \\
Gender & 0.2153 & 1.1016 & 0.2714 \\
Educational level & 0.2133 & 2.5016 & $0.0124^{*}$ \\
Household population & -0.0548 & -0.8059 & 0.4180 \\
Health condition & 0.1145 & 2.3997 & $0.0168^{*}$ \\
Each person income of a family per month & 0.0846 & 2.0304 & $0.0424^{*}$ \\
Income satisfaction & 0.2201 & 1.8924 & 0.0588 \\
Income sources & 0.0507 & 0.5542 & 0.5824 \\
\hline
\end{tabular}


Table 5. Cont.

\begin{tabular}{cccc}
\hline Explanatory Variables & Coefficient & Z-Statistic & $p>|z|$ \\
\hline Average power interruption times & -0.6606 & -3.5235 & $0.0000^{* *}$ \\
Monthly electric charge & -0.1166 & -2.0264 & $0.0424^{*}$ \\
Service time of household appliances & 0.1006 & 2.6868 & $0.0072^{* *}$ \\
Cutting point 1 & -1.86801 & & \\
Cutting point 2 & -1.45096 & & \\
Cutting point 3 & -0.38973 & & \\
Cutting point 4 & 1.128902 & & \\
\hline
\end{tabular}

Note: (1) * Significance level: 5\%; (2) ** Significance level: $1 \%$; (3) LR chi2(12) = 23.12, Prob. > chi2 = 0.017, Log likelihood $=-152.8724$, Pseudo R2 $=0.0703$.

Table 6. Marginal effects of explanatory variables.

\begin{tabular}{cccccc}
\hline Variables & $\mathbf{Y = 1}$ & $\mathbf{Y = 2}$ & $\mathbf{Y = 3}$ & $\mathbf{Y = 4}$ & $\mathbf{Y = 5}$ \\
\hline Age & 0.0737 & -0.0023 & -0.0148 & -0.0064 & 0.0251 \\
Gender & -0.0044 & -0.0067 & -0.0427 & 0.0199 & 0.0737 \\
Educational level & -0.0275 & -0.0420 & 0.0027 & 0.0116 & 0.0452 \\
Household population & 0.0011 & 0.0017 & 0.0110 & 0.0048 & -0.0187 \\
Health condition & -0.0237 & -0.0362 & 0.0230 & 0.0099 & 0.0389 \\
Each person income of a family per month & -0.0331 & -0.0051 & 0.0321 & 0.0139 & 0.0544 \\
Income satisfaction & -0.0046 & -0.0070 & 0.0442 & 0.0192 & 0.0749 \\
Income sources & -0.0010 & -0.0016 & -0.0102 & -0.0044 & 0.0173 \\
Average power interruption times & 0.0137 & 0.0209 & -0.1326 & -0.0576 & -0.2247 \\
Monthly electric charge & 0.0084 & 0.0128 & -0.0082 & -0.0354 & -0.0138 \\
Service time of household appliances & -0.0034 & -0.0053 & 0.0033 & 0.0145 & 0.0566 \\
\hline
\end{tabular}

According to Tables 5 and 6, we can obtain the following results and conclusions:

(1) From Table 5, it can be seen that the log likelihood of the Ordered Probit model is -152.8724 , which is greater than the threshold at a 5\% significance level. Meanwhile, the Pseudo R2 is 0.0703, which indicates a good fitting of the obtained Ordered Probit model. The probability value ( $p$-value) of the likelihood ratio test is $0.017<0.05$, revealing the estimated Ordered Probit regression model has statistical significance.

(2) As shown in Table 5, the $p$-values of six variables, namely 'educational level', 'health condition', 'each person income of a family per month', 'average power interruption times', 'monthly electric charge', and 'service time of household appliances' are all less than 0.05 , which demonstrates that these six variables have statistical significance at a 5\% significance level. Furthermore, the $p$-values of two variables, 'Average power interruption times' and 'Service time of household appliances,' are less than 0.01 , which indicates these two variables have statistical significance at a $1 \%$ significance level. These results show 'educational level', 'health condition', 'each person income of a family per month', 'average power interruption times', 'monthly electric charge', and 'service time of household appliances' are significant factors influencing the well-being of rural residents due to electricity consumption. Dolan P. et al. reviewed many papers and found that poor health, unemployment, lack of social contact, and separation all strongly influence individual subjective well-being in daily life [10]. It can be seen that our findings show a certain consistency with previous research findings.

(3) 'Educational level' has a significant positive influence on the well-being of rural residents. The educational level of a person has a great relationship with his/her job and it can also influence individual outlook on life and value [37,38], which will finally influence the well-being of rural residents due to electricity consumption. As shown in Table 6, the well-being of rural residents due to electricity consumption will improve with an increase in educational level. Specifically, with one grade increase of educational level, such as from 'junior high school' to 'senior high school', the probabilities that the well-being grades of rural residents are 'very 
dissatisfied' and 'not satisfied' will respectively decline by $2.75 \%$ and $4.2 \%$, while the probabilities of being 'generally satisfied', 'relatively satisfied', and 'very satisfied' will increase by $0.27 \%$, $1.16 \%$, and $4.52 \%$, respectively.

(4) 'Health condition' influences the well-being of rural residents significantly and positively. Rural residents with healthy bodies tend to work well and make contributions to society. Meanwhile, they bear fewer burdens and less life pressures, which will finally affect the life satisfaction and well-being of rural residents due to electricity consumption. Specifically, with one grade increase of health condition, such as from 'general' to 'relatively good', the probabilities that the well-being grades of rural residents are 'very dissatisfied' and 'not satisfied' will respectively decline by $2.37 \%$ and $3.62 \%$, while the probabilities of being 'generally satisfied', 'relatively satisfied', and 'very satisfied' will increase by $2.3 \%, 0.99 \%$, and $3.89 \%$, respectively.

(5) 'Each person income of a family per month' is a significant factor positively influencing the well-being of rural residents. Rural residents with high income face lower pressures from living costs, and they have extra money to meet other life needs, such as entertainment, which can significantly improve the quality of life and happiness. Specifically, with one grade increase of each person income of a family per month, such as from '800-1100 yuan' to '1100-1500 yuan', the probabilities that well-being grades of rural residents are 'very dissatisfied' and 'not satisfied' will respectively decline by $3.31 \%$ and $0.51 \%$, while the probabilities of 'generally satisfied', 'relatively satisfied', and 'very satisfied' will increase by $3.21 \%, 1.39 \%$, and $5.44 \%$, respectively.

(6) 'Average power interruption times' has a negative impact on the well-being of rural residents, the regression coefficient of which is the largest among all explanatory variables. Power supply reliability is a priority factor which should be taken into account by power supply companies. High reliability of the power supply and a low power interruption rate can enable power consumers to use power equipment safely and conveniently, which can bring great convenience to rural residents in daily life, and improve their well-being. Specifically, with one grade decrease of average power interruption times, such as from '1-10 times' to 'Never', the probabilities that well-being grades of rural residents are 'very dissatisfied' and 'not satisfied' will respectively decline by $1.37 \%$ and $2.09 \%$, while the probabilities of being 'generally satisfied', 'relatively satisfied', and 'very satisfied' will increase by $13.26 \%, 5.76 \%$, and $22.47 \%$, respectively.

(7) 'Monthly electric charge' has a negative relationship with the well-being of rural residents. On one hand, high electric charge will make rural residents feel high consumption expenditures and life cost. On the other hand, high electric charge will reduce rural residents' expenditure on other aspects. Therefore, high electric charge will lower the well-being of rural residents due to electricity consumption. Specifically, with one grade decrease of monthly electric charge, such as from '50-60 yuan' to '40-50 yuan', the probabilities that well-being grades of rural residents are 'very dissatisfied' and 'not satisfied' will respectively decline by $0.84 \%$ and $1.28 \%$, while the probabilities of 'generally satisfied', 'relatively satisfied', and 'very satisfied' will increase by $0.82 \%, 3.54 \%$, and $1.38 \%$, respectively.

(8) 'Service time of household appliances' matters the well-being of rural residents with a significant and positive effect. Using household appliances such as lighting, watching TV and cooking can bring great convenience to the rural residents' daily lives, which can improve their life experience and happiness. Meanwhile, there is usually a certain inertia for household appliance usage, making household appliance usage a part of daily life. That is, any reduction of existing service time of household appliances may largely affect the daily life of rural residents, while an increase in service time could further enhance the convenience for daily life of rural residents. Specifically, with a $1 \%$ increase in service time of household appliances, the probabilities that well-being grades of rural residents are 'very dissatisfied' and 'not satisfied' will respectively decline by $0.34 \%$ and $0.53 \%$, while the probabilities of being 'generally satisfied', 'relatively satisfied', and 'very satisfied' will increase by $0.03 \%, 1.45 \%$, and $5.66 \%$, respectively. 


\section{Conclusions and Policy Implications}

In this paper, the significant factors influencing rural residents' well-being due to electricity consumption were studied and identified based on 1547 questionnaires handed out in China by employing the Ordered Probit model. Meanwhile, the marginal contributions of significant factors to rural residents' well-being were also analyzed. We draw the following main conclusions:

(1) Among 11 selected factors, six factors, namely educational level, health condition, each person income of a family per month, average power interruption times, monthly electric charges, and service time of household appliances, have statistical significances at a $5 \%$ significance level, which indicate these six factors are the significant factors that influence the rural residents' well-being due to electricity consumption;

(2) Among the six significant factors, educational level, health condition, each person income of a family per month, and service time of household appliances play positive roles in rural residents' well-being, while average power interruption times and monthly electric charges show negative impacts;

(3) Among the significant factors with positive roles, 'educational level' has the greatest marginal effect on rural residents' well-being with the decline of its grade, while the marginal effect of 'health condition' on rural residents' well-being is maximum with the increase of its grade;

(4) Among the significant factors with negative impacts, 'average power interruption times' has the maximum marginal effect on rural residents' well-being.

According to the main conclusions obtained in this paper, to perfect the policy implementation and sustainability related to EUS, improve the well-being of rural residents due to electricity consumption and promote sustainable development of individuals, several policy implications are proposed as follows:

(1) The government should provide related policies to support science and technology skill training for rural residents, to build a platform for information exchange, and to improve the scientific and cultural knowledge levels of rural residents, which can enhance the ability of rural residents to resist uncertain risks and increase income. Meanwhile, the government should provide employment information for rural residents through modern science and technology methods to reduce the information asymmetry in the labor market, and enhance the indemnificatory construction of the labor market as well as improving the labor rights protection system for rural migrant workers in cities.

(2) The health education for rural residents should be improved. Through information dissemination and knowledge sharing, strengthen the health consciousness of rural residents, improve the cognitive abilities about common disease, change the unhealthy lifestyle and personal habits, which aim to reduce the risk of acquiring disease. The government should increase the fiscal expenditures on rural medical health, and establish a health performance assessment mechanism for rural doctors to encourage them to provide timely and effective health information for rural residents. It is also necessary for the government to improve the rural medical security system and medical insurance system, and further develop medical service pricing policy.

(3) The government should take further measures to optimize the crop planting structure as well as agricultural production structure, and improve the agricultural industrialization level. It should also accelerate the industrial as well as spatial transfer of the surplus rural labor force, develop non-agricultural industries, and accelerate the new-type urbanization construction of rural areas.

(4) Echoing the emerging trend of rural consumption, the policy 'home appliance going rural' should be further boosted, including TVs, home computers, and water heaters. Incentive policies such as subsidy and tax exemption should be formulated for home appliance manufacturers. Meanwhile, the government should provide financial subsidies for rural residents who purchase 
particular household appliances, such as TVs and home computers, which can increase electricity consumption and correspondingly improve well-being.

(5) Rural power grid modification and upgrading projects should be further implemented. The weakness of the power distribution network in rural areas, such as the limited maximum power distribution quantity and low voltage, need to be tackled as early as possible. With the implementation of the 'targeted poverty alleviation' policy in China and the construction of new-type urbanization as well as agriculture modernization, the rural power grids should be updated and the stability of the power supply needs to be improved. Meanwhile, with a new round of electric power system reformation, the financing channels for rural power grid upgrades should be developed and expanded, and the supporting funds for rural power grid reconstruction should be in place in a timely fashion.

Acknowledgments: This paper is supported by the National Natural Science Foundation of China (Project Number 71373076).

Author Contributions: Sen Guo, Huiru Zhao and Chunjie Li conceived and designed the experiments; Sen Guo performed the experiments; Haoran Zhao analyzed the data; Sen Guo and Bingkang Li wrote the paper.

Conflicts of Interest: The authors declare no conflict of interest.

\section{References}

1. Stein, E.W. A comprehensive multi-criteria model to rank electric energy production technologies. Renew. Sustain. Energy Rev. 2013, 22, 640-654. [CrossRef]

2. Li, H.; Guo, S.; Cui, L.; Yan, J.; Liu, J.; Wang, B. Review of renewable energy industry in Beijing: Development status, obstacles and proposals. Renew. Sustain. Energy Rev. 2015, 43, 711-725. [CrossRef]

3. Zhao, H.; Guo, S.; Zhang, Q.; Li, C. Social Welfare Evaluation of Electric Universal Service in China: From the Perspective of Sustainability. Sustainability 2014, 6, 4949-4965. [CrossRef]

4. Luo, G.; Guo, Y. Rural electrification in China: A policy and institutional analysis. Renew. Sustain. Energy Rev. 2013, 23, 320-329. [CrossRef]

5. Luo, G.; Zhang, X. Universalization of access to modern energy services in Tibetan rural households-Renewable energy's exploitation, utilization, and policy analysis. Renew. Sustain. Energy Rev. 2012, 16, 2373-2380. [CrossRef]

6. Andrews, F.M.; Withey, S.B. Social Indicators of Well-Being: Americans' Perceptions of Life Quality; Springer Science \& Business Media: New York, NY, USA, 2012; pp. 63-106.

7. The Meaning of Well-Being. Available online: https://en.wikipedia.org/wiki/Well-being (accessed on 21 October 2016).

8. Diener, E. Subjective well-being: The science of happiness and a proposal for a national index. Am. Psychol. 2000, 55, 34-43. [CrossRef] [PubMed]

9. Hills, P.; Argyle, M. The Oxford Happiness Questionnaire: A compact scale for the measurement of psychological well-being. Pers. Individ. Differ. 2002, 33, 1073-1082. [CrossRef]

10. Dolan, P.; Peasgood, T.; White, M. Do we really know what makes us happy? A review of the economic literature on the factors associated with subjective well-being. J. Econ. Psychol. 2008, 29, 94-122. [CrossRef]

11. Sen, A.K. Choice, Welfare and Measurement; Harvard University Press: Cambridge, MA, USA, 1997.

12. Frey, B.S.; Stutzer, A. Happiness and Economics: How the Economy and Institutions Affect Human Well-Being; Princeton University Press: Princeton, NJ, USA, 2002.

13. Daykin, A.R.; Moffatt, P.G. Analyzing ordered responses: A review of the ordered probit model. Underst. Stat. Stat. Issues Psychol. Educ. Soc. Sci. 2002, 1, 157-166. [CrossRef]

14. Pietrovito, F.; Pozzolo, A.F.; Salvatici, L. Internationalization choices: An ordered probit analysis at industry level. Empir. Econ. 2016, 50, 561-594. [CrossRef]

15. Xiong, W. Measuring the monetary policy stance of the People's bank of China: An ordered probit analysis. China Econ. Rev. 2012, 23, 512-533. [CrossRef]

16. Litchfield, J.; Reilly, B.; Veneziani, M. An analysis of life satisfaction in Albania: An heteroscedastic ordered probit model approach. J. Econ. Behav. Organ. 2012, 81, 731-741. [CrossRef] 
17. Mizen, P.; Tsoukas, S. Forecasting US bond default ratings allowing for previous and initial state dependence in an ordered probit model. Int. J. Forecast. 2012, 28, 273-287. [CrossRef]

18. Hung, K.; Cheng, H.W.; Chen, S.S.; Huang, Y.C. Factors that affect credit rating: An application of ordered probit models. Rom. J. Econ. Forecast. 2013, 16, 94-108.

19. Wang, J.; Chang, Z. Social Universal Service: An Empirical Research on China. Econ. Res. J. 2007, 12, 34-45.

20. Wang, J.; Gao, W. Universal service and regulatory policy in Chinese power industry. Res. Econ. Manag. 2008, 1, 31-37.

21. Liao, J.; Wu, C. Study on electric universal subjects and subsidy system in the transition of China's electric industry management. Financ. Trade Econ. 2009, 10, 126-131.

22. Cai, J. Research progress and key issues of electric power universal service in China. J. North China Electr. Power Univ. 2014, 2, 32-37.

23. Li, C.; Cheng, Y.; Zhao, H. Comprehensive utility evaluation of electric power universal service based on utility function, Autom. Electr. Power Syst. 2012, 36, 50-54.

24. Zhao, H.; Li, C.; Chi, N.; Cui, B. Comprehensive evaluation on social value of electric power universal service. Power Syst. Technol. 2009, 33, 99-105.

25. Zhao, H.; Chi, N.; Li, C. Study on income compensation mechanism of electric universal service. Sci. Technol. Ind. 2008, 8, 73-77.

26. Chi, N.; Zhao, H.; Li, C. Study on switching cost and opportunity for implementing electric universal service funding mechanism in China. Technol. Econ. 2008, 27, 78-82.

27. Hoque, N.; Kumar, S. Performance of photovoltaic micro utility systems. Energy Sustain. Dev. 2013, 17, 424-430. [CrossRef]

28. Williams, A.; Simpson, R. Pico hydro-Reducing technical risks for rural electrification. Renew. Energy 2009, 34, 1986-1991. [CrossRef]

29. Saheb-Koussa, D.; Haddadi, M.; Belhamel, M. Economic and technical study of a hybrid system (wind-photovoltaic-diesel) for rural electrification in Algeria. Appl. Energy 2009, 86, 1024-1030. [CrossRef]

30. Lay, J.; Ondraczek, J.; Stoever, J. Renewables in the energy transition: Evidence on solar home systems and lighting fuel choice in Kenya. Energy Econ. 2013, 40, 350-359. [CrossRef]

31. Gómez, M.F.; Silveira, S. The last mile in the Brazilian Amazon-A potential pathway for universal electricity access. Energy Polic. 2015, 82, 23-37. [CrossRef]

32. Shaahid, S.M.; El-Amin, I. Techno-economic evaluation of off-grid hybrid photovoltaic-diesel-battery power systems for rural electrification in Saudi Arabia-A way forward for sustainable development. Renew. Sustain. Energy Rev. 2009, 13, 625-633. [CrossRef]

33. Bhattacharyya, S.C. Energy access problem of the poor in India: Is rural electrification a remedy? Energy Policy 2006, 34, 3387-3397. [CrossRef]

34. Urmee, T.; Harries, D.; Schlapfer, A. Issues related to rural electrification using renewable energy in developing countries of Asia and Pacific. Renew. Energy 2009, 34, 354-357. [CrossRef]

35. Atroshi, I.; Gummesson, C.; Andersson, B.; Dahlgren, E.; Johansson, A. The disabilities of the arm, shoulder and hand (DASH) outcome questionnaire: Reliability and validity of the Swedish version evaluated in 176 patients. Acta Orthop. Scand. 2000, 71, 613-618. [CrossRef] [PubMed]

36. Fangxiao, H.; Meili, Z.; Mengna, L. Empirical research on the influence factors of the new rural endowment insurance system satisfaction based on the SEM. J. Public Manag. 2014, 11, 95-104.

37. White, J. Education, Work and Well-being. J. Philosol. Edu. 2002, 31, 233-247. [CrossRef]

38. Liao, W. How Education Enhances Happiness: The Total Effect and the Mechanism-A Comparison Analysis Based on the Datasets of CGSS2003 and CGSS2008. Master's Thesis, Shanghai University, Shanghai, China, 1 April 2013.

(C) 2016 by the authors; licensee MDPI, Basel, Switzerland. This article is an open access article distributed under the terms and conditions of the Creative Commons Attribution (CC-BY) license (http://creativecommons.org/licenses/by/4.0/). 